\title{
Taking Action Together: A YMCA-based protocol to prevent Type-2 Diabetes in high-BMI inner-city African American children
}

\author{
Lorrene D Ritchie1,2, Sushma Sharma*1,2, Joanne P Ikeda1,2, Rita A Mitchell1,2, Aarthi Raman1,2, Barbara S Green 1,2, \\ Mark L Hudes ${ }^{1,2}$ and Sharon E Fleming 1,2
}

\begin{abstract}
Background: Associated with a tripling in obesity since 1970, type 2 diabetes mellitus (T2DM) in children has risen 910 fold. There is a critical need of protocols for trials to prevent T2DM in children.

Methods/Design: This protocol includes the theory, development, evaluation components and lessons learned from a novel YMCA-based T2DM prevention intervention designed specifically for high-BMI African American children from disadvantaged, inner-city neighborhoods of Oakland, California. The intervention was developed on the basis of: review of epidemiological and intervention studies of pediatric T2DM; a conceptual theory (social cognitive); a comprehensive examination of health promotion curricula designed for children; consultation with research, clinical experts and practitioners and; input from community partners. The intervention, Taking Action Together, included culturally sensitive and age-appropriate programming on: healthy eating; increasing physical activity and, improving self esteem.

Discussion: Evaluations completed to date suggest that Taking Action Together may be an effective intervention, and results warrant an expanded evaluation effort. This protocol could be used in other community settings to reduce the risk of children developing T2DM and related health consequences.
\end{abstract}

Trial registration: ClinicalTrials.gov NCT01039116.

\section{Background}

There is a critical need for trials to be conducted that aim to identify strategies to prevent T2DM mellitus (T2DM) in children. Associated with a tripling in obesity since 1970, T2DM in children has risen 9-10 fold [1]. Additionally, nearly 1 in 6 overweight youth has pre-diabetes [2]. African American youth are among the highest for risk of T2DM with higher rates of obesity and insulin-resistance than other ethnic groups due, in part, to being more insulin resistant [3]. Nearly $50 \%$ of African American children born in the U.S. in 2000 are expected to develop diabetes in their lifetimes [4].

Taking Action Together (TAT) was a controlled community-based intervention protocol developed by research-

\footnotetext{
* Correspondence: sushma@berkeley.edu

1 Dr Robert C and Veronica Atkins Center for Weight and Health, University of California, Berkeley, CA 94720-3100, USA

Full list of author information is available at the end of the article
}

ers at U.C. Berkeley in partnership with the YMCA of the East Bay to reduce risk of T2DM among low-income, high BMI, 9-10 year old African American children through improvements in nutrient intake, physical activity, and self esteem. To avoid stigmatization due to body fatness, focus was placed on improving diet and physical activity rather than on weight loss. Described are the rationale, theory, design, development, implementation, evaluation components, and lessons learned from TAT.

This protocol was designed for delivery to low-income African American children living in disadvantaged, inner-city neighborhoods such as those of East or West Oakland, CA. Compared to a White child living in the Oakland hills (comparatively higher income area), those African American children are more likely to be born low birth weight, live in a low-income household, have parents with only a high school education or less, and have poor access to healthy foods [5]. 
There is a dearth of culturally sensitive interventions that target obesity, diabetes, diet or physical activity among African American youth [6], especially for those living in disadvantaged neighborhoods. Out-of-school settings represent a widely accessible, but largely untapped and under-researched, venue for T2DM prevention. In the U.S. there are $\sim 3,000$ YMCA sites serving nearly 10 million children [7]. Out-of-school programs typically have more flexibility than schools and may be better able to include health-related activities. While healthy benefits from out-of-school programs have been reported [8-12], more studies in 'real world' settings are needed to translate research findings into practice to stem the rapid increase in T2DM.

\section{Hypotheses and specific aims}

Consistent with social cognitive theory, we postulated that development of self efficacy with respect to targeted behaviors would improve children's dietary intake, physical activity, and self esteem which, in turn, would reduce insulin resistance in part by stabilizing body weight. Thus, our main hypothesis was that children in the treatment group would show more favorable changes in insulin resistance than children in the control group following 1 or more 2 years in the program. A secondary hypotheses was that there would be greater improvements in the treatment group in dietary intakes and physical activity. A third hypothesis stated that early markers of behavioral change (dietary and physical activity self efficacy, self esteem, positive behaviors and communications) would be improved in the treatment group when compared to the control.

Thus, the specific aims were (1). To assess the influence of treatment group status on change in insulin resistance (fasting HOMA-IR), (2). To determine the influence of treatment group status on change in intermediate outcomes (diet and physical activity), and (3). To determine the influence of treatment group status on change in potential moderating or mediating variables (self esteem, self efficacy, psychobehavioral characteristics).

\section{Methods/Design}

\section{Selection Criteria (eligibility)}

Inclusion criteria for child participants included: ancestry including at least one African American biological parent; being 9 to 10 years old; having BMI at or above the 85th percentile [13]; free of any systematic disorder or medication known to affect energy metabolism or body weight; and free of severe physical or emotional conditions that could interfere with study participation. The lower limit placed on age was based on concerns that the parents of younger children may be reluctant to consent to a blood draw, and on our assessment that the ethical risk-benefit ratio was less favorable in younger children.
The upper limit was placed to avoid having to sub-group children according to age, loosing statistical power. Broader age ranges would need to be evaluated in subsequent studies.

\section{Primary outcomes}

Change in insulin resistance over 1 or $2 \mathrm{yr}$ of intervention was the primary outcome measure. Fasting glucose and insulin values were used to calculate the homeostatic model parameter - HOMA-IR, defined as fasting glucose $(\mathrm{mmol} / \mathrm{l}) \times$ insulin $(\mu \mathrm{U} / \mathrm{ml}) / 22.5$ [14] and used as an index of insulin resistance [15]. Fasting indices of insulin resistance have been shown to be well correlated with estimates obtained using the "gold standard" methods of assessing insulin resistance using the euglycemic-hyperinsulinemic clamp in 9 - 10 year old children [16] and oral glucose tolerance test in premenarchal girls [17], and these indices have been used to show that overweight children are at greater risk for type 2 diabetes than normal weight children [18]. Lower risks are associated with this fasting index since it requires only a single veinpuncture and, thus, is preferable for use in children. The study's second primary outcome, change in glycosylated hemoglobin (HbA1c), was assessed by quantifying HbA1c using a dual HPLC method which detects variants common in African Americans that interfere will interpretation of HbA1c data $[19,20]$.

\section{Demographic and Secondary outcomes}

Anthropometric variables (Table 1), including child body weight and height, were measured and used to calculate BMI and BMI z-score. Additionally, waist and hip circumferences, and percent body fat were measured.

Hematological variables other than the primary outcomes previously described, included measurement of non-esterified fatty acid (NEFA) concentrations, which were used to calculate adipocyte fatty acid insulin sensitivity (ISI-FFA) by the formula:[2/(insulin $\times$ NEFA) +1$]$ [21]. Additionally, pubertal stage was estimated following assessment of fasting plasma concentrations of specific sex hormones (Table 1).

Dietary variables included calculation of nutrient intakes and servings of foods consumed by children, following data analysis from 3-day food diary records (Table 1). Additionally, assessments were made of child food habits, preferences, self efficacy and nutrition knowledge; and of family food habits and stages of change with respect to specific healthy food habits.

Physical activity of child participants was assessed from 3-day physical activity diary records, and physical fitness was assessed using the Pacer lap run test that is administered as part of the California Fitnessgram evaluations (Table 1). Additionally, child physical activity habits, 
Table 1: Evaluation Measures in Taking Action Together

\begin{tabular}{|c|c|}
\hline Measurement & Procedure \&/or reference \\
\hline \multicolumn{2}{|l|}{ Anthropometry (child) } \\
\hline Waist \& hip circum and ratio & With plastic non-elastic tape [50] \\
\hline Weight, height, BMI and BMIz & Wt: digital electronic scale, Ht: portable stadiometes, BMIz Calc [13] \\
\hline$\%$ Body fat & BIA [50], \% Body Fat Horlick's equation [51,52] \\
\hline \multicolumn{2}{|l|}{ Glucoregulation (Child) } \\
\hline Fasting Glucose, Insulin & Commercially available kits [50] \\
\hline HOMA-IR & Calculation of insulin resistance [14] \\
\hline HbA1c, C-Peptide, NEFA & HbA1c [19,20]; C-Pep \& NEFA, (Linco \& Wako kits). \\
\hline Acanthosis nigricans & Appearance of skin on back of neck with 0-4 scale of severity [53] \\
\hline \multicolumn{2}{|l|}{ Diet (child) } \\
\hline Dietary intakes & Food diary [54,55]; average intake and servings [36] \\
\hline Dietary habits \& Nutrition knowledge & After-School Student Questionnaire self-efficacy $[50,56]$ \\
\hline \multicolumn{2}{|l|}{ Physical Activity and Fitness (child) } \\
\hline Physical activity \& fitness & 3-day PA diaries [55], Lap run [57] \\
\hline PA habits \& knowledge & California Dept. of Education's Healthy Kids Survey [58] \\
\hline Athletic competence & Harter self-perception profile for children [59] \\
\hline \multicolumn{2}{|l|}{ Self efficacy } \\
\hline Diet self-efficacy & ASSQ self-efficacy questions [56] \\
\hline PA self-efficacy & Child's Self-Assessment for Physical Activity (CSAAPA) $[57,60]$ \\
\hline \multicolumn{2}{|l|}{ Self-esteem \& Body Image (child) } \\
\hline Self-worth \& social acceptance & Harter self-perception profile for children [59] \\
\hline Body satisfaction & Validated in African American adults [61], modified [62] \\
\hline Self-esteem & Behavioral Assessment System for Children, BASC-2 [34], child report \\
\hline \multicolumn{2}{|l|}{ Behavior and Communications (child) } \\
\hline Conduct problems \& activities & BASC-2 [34], parent report and child report \\
\hline Communication \& social skills & BASC-2 [34]; parent and child report \\
\hline \multicolumn{2}{|l|}{ Adult and Family Assessments } \\
\hline Family food behaviors & Shopping, meal preparation and family eating [63] \\
\hline Change for diet and PA & Fruit \& vegetables [64], avoidance of high-fat [64,65], exercise [66] \\
\hline Family PA habits \& weight & $\begin{array}{l}\text { Family member's habits, duration of activity, and prevalence of } \\
\text { overweight [50] }\end{array}$ \\
\hline \multicolumn{2}{|l|}{ Additional Potential Confounding Variables } \\
\hline Family environment \& SEI & Moos Family Environment Scale [67], Socioeconomic index [63] \\
\hline Family \& Intrauterine history of T2DM & American Diabetes Association instrument [68] \\
\hline Polyovarian syndrome & (female child participants only) [50] \\
\hline Pubertal stage & Estradiol (E2), luteinizing hormone $[50,69]$ \\
\hline
\end{tabular}

knowledge, competence and self efficacy were assessed using subjective questionnaires.

Psychosocial variables were assessed using subjective questionnaires administered to the child and/or parent (Table 1). These variables included measures of self esteem, body satisfaction, behavior and communications.
Sociodemographic factors were measured using subjective questionnaires administered to an adult family member. Factors of interest included age and gender of adults, education, housing and employment status.

Other subjective data were obtained also from questionnaires administered to the adult family member. Factors of interest included family history and intrauterine 
risk of T2DM, diagnoses of girls for polyovarian syndrome, and selected characteristics of the family environment.

\section{Theoretical model}

Recognizing the interplay between individual characteristics and one's social environment in determining health-related behaviors, Bandura's Social Cognitive Theory (SCT) was selected as the foundation for TAT [22]. In youth, modest improvements in social, cognitive, dietary and exercise outcomes have been achieved when programs utilized SCT $[23,24]$. Consistent with SCT, we postulated that strong self efficacy would positively affect diet quality, physical activity and energy balance of children which, in turn, would reduce insulin resistance directly or indirectly via effects on body fatness (Figure 1 ). An extensive research literature has demonstrated that several factors (e.g., child pubertal stage, self esteem, psycho-behavioral status) are able to interfere with or promote these relationships.

\section{Intervention goals}

The development of the TAT intervention was informed by a comprehensive review of the literature in conjunction with recommendations from a panel of national experts on policy and program initiatives to prevent T2DM in children [25]. The review revealed that the most efficacious programs aimed to improve both diet and physical activity.

\section{Dietary goals}

Based on a 2003 review of the dietary determinants of obesity [26], the following dietary goals were selected for TAT: increase intake of fruit, vegetables, whole grains, and low-fat dairy foods; reduce intake of high-fat and high-sugar foods and beverages; and sharpen awareness of cues to satiety.

\section{Physical activity goals}

It has been recommended that children participate in a cumulative total of 60 minutes or more daily of moderate-to-vigorous physical activity [27]. To promote sus-

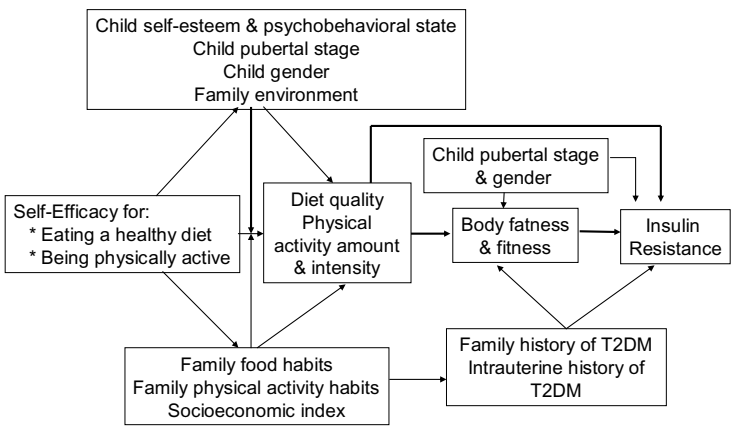

Figure 1 Theoretical model for Taking Action Together study tained adoption of an active lifestyle, activities should be both fun and doable by children; and overweight children should begin physical activities at a low intensity and duration, gradually increasing as competence is gained [28]. The TAT physical activity goal was to increase time spent in moderate-to-vigorous intensity physical activity by developing skills, knowledge and self efficacy with respect to having endurance and being flexible, strong, coordinated, quick and agile.

\section{Self-esteem goals}

Studies have shown that overweight children tend to have lower body satisfaction and, in some cases, lower self esteem than normal weight children [29]. Exposure to teasing exacerbates the effect [30]. Poor self esteem is often associated with negative behavior [29]. Further, emphasis was placed on self-esteem building since poor self esteem can interfere with the development and maintenance of positive eating and physical activity behaviors, and since efforts to improve these behaviors can unintentionally negatively influence self esteem. Our goal for the self-esteem component was to develop five social and emotional competencies:awareness of one's strengths, challenges, behaviors and styles of interacting; ability to effectively interact and communicate with others; respect for self and others; ability to describe self using art, writing and verbal means; and ability to assess positive change in one's behavior and personal interactions. Consistent with the tenet of 'health at every size' [31], goals for body weight were not instituted. Improving insulin sensitivity, regardless of weight loss, has been reported to reduce risk of metabolic disease [32]. Further, to avoid stigmatization due to body fatness, focus was placed on improving diet and physical activity rather than on body weight.

Consultation with multi-disciplinary and community experts To inform the multiple components of TAT, we collaborated with a team of experts specializing in a wide range of disciplines including nutrition, exercise physiology, public health, psychology, medicine, education, and cultural sensitivity (Table 2). In addition, advice was sought on curriculum, program activities, participant retention strategies, opportunities for program enhancement and expansion, and venues for disseminating research findings.

The TAT Advisory Board (Table 2) included community members who had successfully developed relevant programs for school-aged children and their families; and members with experience working specifically with inner-city residents and low-income African American families. The Advisory Board was convened yearly; ad hoc consultations with individual members were undertaken as needed. Additionally, we capitalized on established and essential working relationships with local community and state partner organizations including 
Table 2: Coordinated and Complementary Roles of Research Staff, Consultants and Advisory Board Members for the Taking Action Together Project

\begin{tabular}{|c|c|c|c|}
\hline EXPERTISE & $\begin{array}{c}\text { UCB } \\
\text { Researchers }\end{array}$ & Collaborators \& Consultants 1 & $\begin{array}{r}\text { Board } \\
\text { members }{ }^{2}\end{array}$ \\
\hline \multicolumn{4}{|l|}{ INTERVENTION } \\
\hline Adult education & $\sqrt{ }$ & & $\sqrt{ }$ \\
\hline Cultural relevance & & $\sqrt{ }$ & $\sqrt{ }$ \\
\hline Curriculum & $\sqrt{ }$ & & $\sqrt{ }$ \\
\hline Family involvement & & $\sqrt{ }$ & $\sqrt{ }$ \\
\hline Medical management & & $\sqrt{ }$ & \\
\hline Nutrition & $\sqrt{ }$ & & $\sqrt{ }$ \\
\hline Physical education & $\sqrt{ }$ & $\sqrt{ }$ & $\sqrt{ }$ \\
\hline Process evaluation & $\sqrt{ }$ & & \\
\hline Self-esteem & $\sqrt{ }$ & $\sqrt{ }$ & $\sqrt{ }$ \\
\hline Study management & $\sqrt{ }$ & & \\
\hline \multicolumn{4}{|l|}{ EVALUATION } \\
\hline Anthropometry & $\sqrt{ }$ & $\sqrt{ }$ & $\sqrt{ }$ \\
\hline Biochemical & $\sqrt{ }$ & $\sqrt{ }$ & $\sqrt{ }$ \\
\hline Diet & $\sqrt{ }$ & & $\sqrt{ }$ \\
\hline Family demographics \& characteristics & $\sqrt{ }$ & $\sqrt{ }$ & \\
\hline Physical activity \& fitness & $\sqrt{ }$ & $\sqrt{ }$ & $\sqrt{ }$ \\
\hline Self-esteem \& behavior & $\sqrt{ }$ & $\sqrt{ }$ & $\sqrt{ }$ \\
\hline Statistics \& data analysis & $\sqrt{ }$ & & \\
\hline \multicolumn{4}{|l|}{ DISSEMINATION } \\
\hline Behavioral scientists & & $\sqrt{ }$ & \\
\hline Cooperative Extension & $\sqrt{ }$ & & \\
\hline Medical community & $\sqrt{ }$ & $\sqrt{ }$ & $\sqrt{ }$ \\
\hline Research scientists & $\sqrt{ }$ & $\sqrt{ }$ & $\sqrt{ }$ \\
\hline $\begin{array}{l}\text { YMCA and other after-school/community } \\
\text { venues }\end{array}$ & & & $\sqrt{ }$ \\
\hline \multicolumn{4}{|c|}{$\begin{array}{l}{ }^{1} \text { Academic collaborators and consultants included researchers at University of California (UC) Berkeley, UC San Francisco, UC Riverside, Brock } \\
\text { University in Toronto, and UC Cooperative Extension. } \\
{ }^{2} \text { Advisory board members included representation from diverse programs including the Food Stamp and Nutrition Education Program } \\
\text { (youth and adult programs), Expanded Food and Nutrition Education Program (EFNEP), } 5 \text {-a-Day Power Play, Sports Play and Active Recreation } \\
\text { for Kids (SPARK), California Adolescent Nutrition and Fitness Program (CanFIT), and the YMCA of the East Bay. Other collaborating institutions } \\
\text { and organizations with a long history of involvement in the inner-city Oakland community included Children's Hospital and Research } \\
\text { Institute Oakland, the California Department of Health Services and UC county-based Cooperative Extension. }\end{array}$} \\
\hline
\end{tabular}

county-based Cooperative Extension programs, and federal USDA-funded food supplementation programs such as FSNEP and EFNEP.

\section{Control group programming}

In contrast to the intervention group, contact with child participants and families in the control group occurred primarily during recruitment and yearly data collection, and there was no hands-on involvement in intervention activities. To encourage participation and maximize study retention while minimizing the 'Hawthorne' effect [33] and dissatisfaction with minimal intervention, control families received information focusing on community opportunities for health promoting activities in the mail monthly, and control children were offered a free week of traditional YMCA summer day camp. 
Trial design, participant recruitment and group assignment Trial design

This controlled, prospective, non-randomized trial was approved by the institutional review board (ethics committees) at the University of California -- Berkeley and San Francisco. Parental informed consent was obtained for all participants. To achieve adequate sample size, three cohorts of participants were recruited over three successive years (Table 3 ).

\section{Recruitment}

Announcements were distributed at elementary schools and other venues within the targeted communities. Incentives, benefits and risks to participants were conveyed in these announcements. Recruitment was restricted to community venues in regions of Oakland habitated by low income African American families. Because families in these regions tend to be fluid, no restrictions were placed on family structure, ethnicity of the adult caregivers or relationship to the child participant. Data were collected from only 1 child per family. As it happened, similar numbers of families self-selected into each of the two sites and similar numbers were included at baseline (Control group, $\mathrm{n}=111$; Treatment group, $\mathrm{n}=$ 124; Table 3). We expected to achieve a 50:50 ratio for boys:girls, and achieved a ratio at baseline of 44:56.

\section{Assessing bias due to motivation}

The potential for bias due to motivation was estimated by comparing dropout rates between the two groups during the 1 or 2 year intervention period. Dropout rates for control and intervention groups were similar after both 1

Table 3: Taking Action Together Project Plan - Participants by Group

\begin{tabular}{ccc}
\hline & Control group & Intervention group \\
\hline Baseline & Number of participants (boys; girls) \\
Cohort 1 & $51(21 ; 30)$ & $52(20 ; 32)$ \\
Cohort 2 & $28(16 ; 12)$ & $35(16 ; 19)$ \\
Cohort 3 & $32(14 ; 18)$ & $37(16 ; 21)$ \\
Total & $111(51 ; 60)$ & $124(52 ; 72)$ \\
\hline End of 1st Year Follow-up & $37(14 ; 23)$ \\
Cohort 1 & $33(13 ; 20)$ & $18(7 ; 11)$ \\
Cohort 2 & $20(11 ; 9)$ & $14(7 ; 7)$ \\
Cohort 3 & $14(9 ; 5)$ & $69(28 ; 41)$ \\
Total & $67(33 ; 34)$ & $35(17: 28)$ \\
\hline End of 2nd Year Follow-up & $26(10 ; 16)$ & $24(10 ; 14)$ \\
Cohort 1 & $12(6 ; 6)$ & $11(7 ; 4)$ \\
Cohort 2 & $38(16 ; 22)$ & \\
Total & & \\
\hline
\end{tabular}

year $(40 \%$ versus $44 \% ; \mathrm{p}=0.46)$ and 2 years $(66 \%$ versus $72 \% ; \mathrm{p}=0.52)$ of programming. Furthermore, when information collected at baseline was compared for dropouts from the control versus treatment groups, no significant differences were found. As examples, mean baseline insulin resistance (HOMA-IR) values of children who dropped out of the control versus treatment groups during the first year were 2.61 and 2.76, respectively ( $\mathrm{p}=$ 0.67 ), and means for dropouts during two years of programming were 2.59 and 2.55 , respectively $(\mathrm{p}=0.91)$. Additionally, baseline insulin resistance values for children who completed two years of programming versus those who did not were not significantly different (HOMA-IR mean values: 2.56 and 2.53, respectively; $\mathrm{p}=$ 0.90).

\section{Reducing bias due to non-randomization}

Families self-selected to attend programming at one of the two sites, and this selection preceded information regarding the assignment of treatment to that site; ie. when selecting a site, families did not know whether they would be in the control or the intervention group (Figure 2). Prior to beginning Wave 1 , and after families selected their preferred site, a toss of the coin was used to determine which of the two sites would be the intervention site. For subsequent waves, families still were unaware of treatment status when choosing their preferred site. The two sites were similar in many respects including their staffing, characteristics of the facility, economic and cultural characteristics of neighborhood residents, crime rates, and general lack of health care, supermarkets and parks. Although contamination across sites may not have been entirely eliminated, staff (research and YMCA) were alerted to report any interactions that could suggest con-




tamination. We were not made aware of any such reports during the 3-year intervention period.

At the analytical stage, statistical analyses for differences by treatment group will be controlled, if needed, for covariates including child age, gender, socioeconomic status, pubertal stage or other potential anthropometric, dietary, physical activity, self esteem, behavior or family confounders (for a comprehensive list of variable assessed, refer to Table 1). The necessity for adjustment for a particular variable will be determined in a preliminary analysis in the following way. Any variable modestly related $(\mathrm{p}<0.25)$ to BOTH treatment group status and the change in the outcome variable will be considered to be a potential confounder and included in analytic models. Since subjects were not randomized into groups, analyses will be statistically adjusted for baseline outcome values (analysis of covariance) as groups may not have been equivalent at baseline for these outcomes (some examples are shown in Table 4).

\section{Data management and statistical analyses}

The project was designed to allow change in outcome variables to be calculated for each participant using a prepost experimental design. Measures were taken at baseline prior to exposure to intervention, then again following either 1 or 2 years of programming (Table 5). To achieve a balanced design, similar numbers of control and treatment participants were recruited into each of the three cohorts, and similar numbers of boys and girls were recruited into each treatment group (Table 3). Data for cohorts will be combined at the analysis stage.

\section{Quantitative data}

Quantitative data were managed using computer programs including Microsoft Excel, EpiData, BASC-2 software [34], USDA Nutrient Database [35] and MyPyramid Equivalents Database [36]. Data were double entered and edit checks were incorporated into the data entry program to identify data entry errors. For psychosocial, knowledge and attitude measures, scales will be developed as necessary and compared as described above.

Mean changes in the quantitative outcome variables of interest (HOMA-IR and secondary anthropometric, dietary and activity variables) over one or two intervention years will be evaluated using multiple regression techniques. Adjustment for multiple comparisons will not be made, and with values for $\mathrm{p}<0.05$ considered statistically significant [37]. In addition, because some of these outcome measures are considered to be intermediary or confounding variables, we will use multiple linear regression to examine the effect of intervention on the primary outcome variable of interest (HOMA-IR), adjusting for baseline HOMA-IR, BMI z-score, psychosocial measures such as self esteem, diet and physical activity behaviors, and other potentially relevant factors such as family and (to account for genetic differences in response to intervention) intrauterine history of T2DM. The correlations of all potential covariates with both the dependent and independent variables will be examined, and variables that correlate at $\mathrm{p}<0.25$ with both variables will be included in the models.

Initially, we will examine the regression coefficient for intervention status (a dummy variable where 1 = intervention group, 0 = control group) in a simple regression model. Using change in HOMA-IR as one dependent variable example, we will model as follows:

$\Delta$ fasting HOMA - IR $=\beta_{0}($ constant $)+\beta_{1}($ intervention status $)+$ $\beta_{2}$ (baseline fasting HOMA - IR ) + error term

Next, we will examine the effects of other explanatory and/or confounding variables to determine whether they explain the effects of intervention status (if any) using as an example:

$\Delta$ fasting HOMA $-\mathrm{IR}=\beta_{0}($ constant $)+\beta_{1}($ intervention status $)+$

$$
\begin{aligned}
& \left.\beta_{2} \text { (baseline fasting HOMA - IR }\right) \\
& +\ldots .+\beta_{i+2}(\text { baseline covariate } \mathrm{i})+\text { error term }
\end{aligned}
$$

\section{Qualitative data}

Qualitative data from interviews with families will be transcribed and analyzed using grounded theory, a qualitative approach that is used to analyze social processes present within human interactions [38]. Application of the theory can result in explanations of important family processes or structures that are grounded in the empirical data. Major themes can be inductively derived from the data to articulate the dynamics of psychosocial family environment.

\section{Statistical power and sample size}

When this study was originally conceptualized in 2003, few data were available in the literature describing the variability in insulin resistance, assessed using fasting HOMA-IR, among overweight African American children. Thus, since it was expected that the qualifying children would be hyperinsulinemic but not hyperglycemic, sample size was estimated using values for plasma insulin. For evaluation of the effectiveness of the intervention, a sample of 50 children in the intervention group and another 50 in the control group was determined to allow detection of a difference in plasma insulin levels of $4 \mu \mathrm{U} /$ $\mathrm{ml}$, assuming an initial fasting plasma insulin of $30 \mu \mathrm{U} / \mathrm{ml}$ [39-41], a standard deviation of $7.2 \mu \mathrm{U} / \mathrm{ml}$ [42] and a correlation coefficient of 0.6 between initial and final values in the control group (Type I error $=0.05$, and Type II error $=0.20)$. A total sample size of 150 participants at baseline (75 per group) was initially planned for, based on an estimated yearly attrition rate of $33 \%$. Because the attrition rate was higher than anticipated following the first year of Wave 1, the number of participants was increased during the course of this study. 
Table 4: Some baseline characteristics of participants in the control and intervention groups ( $p$-value for difference by group).

\begin{tabular}{|c|c|c|c|c|}
\hline & Characteristic & $\begin{array}{l}\text { Control } \\
\text { (mean) }\end{array}$ & $\begin{array}{l}\text { Intervention } \\
\text { (mean) }\end{array}$ & p-value \\
\hline \multirow[t]{22}{*}{ Child } & Age (yr) & 9.84 & 9.85 & 0.92 \\
\hline & BMI z-score & 2.00 & 2.05 & 0.52 \\
\hline & Waist-to-hip ratio & 0.88 & 0.89 & 0.36 \\
\hline & $\%$ body fat & 36.2 & 36.3 & 0.90 \\
\hline & Pubertal stage (1-5 scale) & 2.28 & 2.17 & 0.54 \\
\hline & Fasting $\mathrm{HbA} 1 \mathrm{c}(\%)$ & 5.18 & 5.14 & 0.44 \\
\hline & Fasting HOMA-IR & 2.49 & 2.51 & 0.94 \\
\hline & Fasting ISI-FFA & 0.43 & 0.42 & 0.72 \\
\hline & Energy intake (kcal/day) & 1829 & 1887 & 0.53 \\
\hline & Fat intake (g/day) & 75.2 & 73.0 & 0.62 \\
\hline & Carbohydrate intake (g/day) & 220 & 245 & 0.04 \\
\hline & Protein intake (g/day) & 71.5 & 67.9 & 0.38 \\
\hline & Whole grains intake (servings/day) & 0.70 & 0.73 & 0.77 \\
\hline & Fruit \& vegetable intake (servings/day) & 2.06 & 2.38 & 0.10 \\
\hline & Dairy intake (servings/day) & 1.27 & 1.21 & 0.59 \\
\hline & Nutrition knowledge (1-22 scale) & 9.63 & 9.96 & 0.25 \\
\hline & Food preferences (7-25 scale) & 16.0 & 16.3 & 0.32 \\
\hline & Snack habits (1-5 scale) & 2.41 & 2.45 & 0.76 \\
\hline & Fitness ( $\mathrm{ml} \mathrm{O} 2 / \mathrm{min} / \mathrm{kg}$ body $\mathrm{wt}$ ) & 41.8 & 43.8 & 0.26 \\
\hline & Moderate- \& high-intensity physical activity (min/day) & 89.7 & 104.4 & 0.31 \\
\hline & Global self-worth (1-4 scale) & 2.98 & 3.04 & 0.55 \\
\hline & Athletic competence (1-4 scale) & 2.76 & 2.82 & 0.47 \\
\hline \multirow[t]{8}{*}{ Family or Adult } & Age of adult responder (yr) & 37.1 & 38.5 & 0.30 \\
\hline & SEI (4-12 range) & 8.42 & 8.29 & 0.59 \\
\hline & Family History of T2DM (0-2 scale) & 0.13 & 0.20 & 0.18 \\
\hline & Intrauterine risk for T2DM (0-2 scale) & 0.34 & 0.32 & 0.82 \\
\hline & Food habits (7-36 scale) & 21.9 & 23.0 & 0.04 \\
\hline & Physical activity habits (3-15 scale) & 11.7 & 12.2 & 0.28 \\
\hline & Family Cohesion (1-4 scale) & 3.47 & 3.45 & 0.81 \\
\hline & Family Conflict (1-4 scale) & 0.94 & 0.85 & 0.38 \\
\hline
\end{tabular}

\section{Training}

\section{Control staff}

YMCA staff at the control site received the in-house YMCA training provided to all new staff, and a limited 1hr orientation to the project.

\section{Intervention staff}

Implementers of the TAT intervention included UC Berkeley staff and students, and YMCA staff. The adultto-child ratio was 1:8 for most intervention activities. Site instructors and key YMCA staff received in-house YMCA training, plus program-specific training prior to commencement of each program year, followed by weekly and monthly training (referred to hereafter as "initial" and "continuing" training, respectively). Initial training aimed to provide an understanding of expectations with respect to participant confidentiality, safety and communications; the nature of each curriculum component; and the influence of self esteem and of eating and physical activity behaviors on risk of T2DM. Continuing training focused on team building $(3 \mathrm{hr} / \mathrm{yr})$, health lifestyle challenges in an obesigenic environment $(3 \mathrm{hr} / \mathrm{yr})$, managing challenging behaviors in children $(8 \mathrm{hr} / \mathrm{yr})$, use of social cognitive theory in practice $(2 \mathrm{hr} / \mathrm{yr})$, nutrition lesson-specific training (40 hr/yr), physical activity les- 
Table 5: Taking Action Together Project Plan - Project Timeline

\begin{tabular}{|c|c|c|c|c|c|c|c|c|c|c|c|c|c|c|c|c|}
\hline \multirow{2}{*}{$\begin{array}{l}\text { Project Year1 }^{1} \\
\text { Develop program }\end{array}$} & \multicolumn{4}{|c|}{$1^{3}$} & \multicolumn{4}{|c|}{$2^{3}$} & \multicolumn{4}{|c|}{$3^{3}$} & \multicolumn{4}{|c|}{$4^{3}$} \\
\hline & $A$ & B & $\mathrm{C}$ & $\mathrm{D}$ & & & & & & & & & & & & \\
\hline Refine program & & & & & $A$ & B & $\mathrm{C}$ & $\mathrm{D}$ & $A$ & B & $\mathrm{C}$ & $\mathrm{D}$ & & & & \\
\hline Convene Advisory Board & & B & & & & B & & & & B & & & & B & & \\
\hline Train staff & & & $\mathrm{C}$ & $\mathrm{D}$ & $A$ & B & $\mathrm{C}$ & $\mathrm{D}$ & $A$ & B & $C$ & $\mathrm{D}$ & $A$ & B & $\mathrm{C}$ & \\
\hline Conduct process evaluation & & & & & A & B & $\mathrm{C}$ & $\mathrm{D}$ & A & B & $C$ & $\mathrm{D}$ & A & B & $\mathrm{C}$ & $\mathrm{D}$ \\
\hline \multicolumn{17}{|l|}{ Recruit study participants } \\
\hline First cohort $(n=103)$ & & & $\mathrm{C}$ & $\mathrm{D}$ & & & & & & & & & & & & \\
\hline Second cohort $(n=63)$ & & & & & & & $\mathrm{C}$ & $\mathrm{D}$ & & & & & & & & \\
\hline Third cohort $(n=69)$ & & & & & & & & & & & $\mathrm{C}$ & $\mathrm{D}$ & & & & \\
\hline \multicolumn{17}{|l|}{ Provide intervention ${ }^{2}$} \\
\hline First cohort & & & & & $A$ & B & $\mathrm{C}$ & $\mathrm{D}$ & $A$ & B & $\mathrm{C}$ & $\mathrm{D}$ & $A$ & & & \\
\hline Second cohort & & & & & & & & & A & B & $\mathrm{C}$ & $\mathrm{D}$ & A & B & $\mathrm{C}$ & $\mathrm{D}$ \\
\hline Third cohort & & & & & & & & & & & & & A & B & $\mathrm{C}$ & $\mathrm{D}$ \\
\hline \multicolumn{17}{|c|}{ Perform impact measures $\left(0=\text { pre-study; } 1=1^{\text {st }} Y r \text { follow-up; } 2=2^{\text {nd }} Y r \text { follow-up }\right)^{2}$} \\
\hline First cohort & & & & 0 & & & & 1 & & & & 2 & & & & \\
\hline Second cohort & & & & & & & & 0 & & & & 1 & & & & 2 \\
\hline Third cohort & & & & & & & & & & & & 0 & & & & 1 \\
\hline
\end{tabular}

son-specific training (10 hr/yr), self-esteem lesson-specific training $(10 \mathrm{hr} / \mathrm{yr})$, and strategies for motivating families (Table 6).

\section{Intervention curricula and delivery to children}

Each program year began with a kick off to integrate all elements of the curricula in a fun-filled, action-packed 2 weeks of YMCA day-camp. Children were provided ample opportunities to bond with each other and staff to promote continued participation. A celebratory family event was held at the end of the 2 weeks for children to showcase the program to their families.

Yearly schedule of child activities included 10 days $(8 \mathrm{hr}$ per day) of program-specific summer day-camp, plus 1 (2-hr) session/wk, 3 weeks per month, 11.5 month for a total of $150 \mathrm{hr}$ (50\% devoted to physical activity and 25\% devoted each to nutrition and self-esteem building) for children.

With goals and a theoretical model for TAT as a guide, we examined relevant curricula from peer-reviewed scientific literature and on-line sources. Materials were evaluated for: age-appropriateness; socio-cultural relevance; body weight neutral (incorporating a 'health at every size' approach); current within 10 years; experiential (a handson, rather than didactic, approach to learning); and resonance with program goals. No single program curriculum was identified that met all project criteria. Thus, select materials were used from a variety of curricula and, as needed, adapted for use with our target population.

\section{Educational components}

Lessons and activities focused on improvements in dietary quality and quantity, increased time in moderateto-vigorous activity, and healthy self-esteem building through strengthening of cultural pride and social and behavioral competence. Conceptual elements included knowledge and skill building, modeling, goal setting, selfassessment, practice and reinforcement. Educational strategies included individual practice, cooperative learning, and individual and group discussions. Modules (6 modules, 5 weeks each), and lessons within modules, were sequenced to equip children with knowledge, skills, self efficacy and intentions to make healthy diet and physical activity choices. Examples of lessons delivered in this program are available online http://www.cnr.berkeley.edu/cwh/. 
Table 6: Training Components and Content

\begin{tabular}{|c|c|c|}
\hline Program Component & Training time & Content \\
\hline $\begin{array}{l}\text { 1. Introductions, team-building, project } \\
\text { overview }^{1}\end{array}$ & $\begin{array}{l}1 \mathrm{hr} \text { during initial and yearly training } \\
\text { (+3 hr additional during year-long } \\
\text { program) }\end{array}$ & $\begin{array}{l}\text { Introduce personnel roles. Describe the research project } \\
\text { and program. Build team atmosphere. Introduce Body } \\
\text { Positive and Health at Every Size concepts. }\end{array}$ \\
\hline $\begin{array}{l}\text { 2. Healthy lifestyle challenges in an } \\
\text { obesogenic environment }{ }^{2}\end{array}$ & $1 \mathrm{hr}(+0 \mathrm{hr})$ & $\begin{array}{l}\text { Introduce nutrition, physical activity and self-esteem } \\
\text { goals. Discuss challenges African American families } \\
\text { experience in inner-city Oakland in efforts to live a } \\
\text { healthy lifestyle. }\end{array}$ \\
\hline $\begin{array}{l}\text { 3. Managing challenging behaviors in } \\
\text { children }^{2}\end{array}$ & $1 \mathrm{hr}(+8 \mathrm{hr})$ & $\begin{array}{l}\text { Introduce positive behavioral management approaches } \\
\text { and describe how to effectively develop social skills and } \\
\text { problem-solving abilities in children. }\end{array}$ \\
\hline 4. Social cognitive theory (SCT) in practice ${ }^{2}$ & $1 \mathrm{hr}(+2 \mathrm{hr})$ & $\begin{array}{l}\text { Understanding and using self-observation, peer } \\
\text { modeling, feedback, verbal encouragement, mastery } \\
\text { through trials of increasing difficulty. }\end{array}$ \\
\hline $\begin{array}{l}\text { 5. Nutrition }{ }^{2} \\
\text { General } \\
\text { Lesson-by-lesson }\end{array}$ & $\begin{array}{l}1 \mathrm{hr}(+2 \mathrm{hr}) \\
0 \mathrm{hr}(+40 \mathrm{hr})\end{array}$ & $\begin{array}{l}\text { Describe components of healthy diet, considerations of } \\
\text { African American culture, income, food availability and } \\
\text { transportation; demonstrate use of SCT3, importance of } \\
\text { fun. }\end{array}$ \\
\hline $\begin{array}{l}\text { 6. Physical activity² } \\
\text { General } \\
\text { Lesson-by-lesson }\end{array}$ & $\begin{array}{l}1 \mathrm{hr}(+2 \mathrm{hr}) \\
0 \mathrm{hr}(+10 \mathrm{hr})\end{array}$ & $\begin{array}{l}\text { Discuss barriers, use of Health at Every Size concept and } \\
\text { SCT to increase activity self-efficacy, motivational } \\
\text { strategies, cultural preferences and considerations. }\end{array}$ \\
\hline $\begin{array}{l}\text { 7. Self-esteem² } \\
\text { General } \\
\text { Lesson-by-lesson }\end{array}$ & $\begin{array}{l}1 \mathrm{hr}(+2 \mathrm{hr}) \\
0 \mathrm{hr}(+10 \mathrm{hr})\end{array}$ & $\begin{array}{l}\text { Describe contributors to and effect of positive self- } \\
\text { esteem, cultural differences in expression. Discuss } \\
\text { strategies to develop self-esteem using Body Positive } \\
\text { approach, preventing harm. }\end{array}$ \\
\hline 8. Motivating families ${ }^{2}$ & $1 \mathrm{hr}(+1 \mathrm{hr})$ & $\begin{array}{l}\text { Influence of parenting style, family food and activity } \\
\text { practices, and community environment on } \\
\text { development of healthy behaviors; motivational } \\
\text { strategies; cultural considerations. }\end{array}$ \\
\hline
\end{tabular}

\footnotetext{
${ }^{1}$ Separate sessions for Control and Intervention site staff.
}

2 Intervention site staff only.

\section{Nutrition component}

The core nutrition lessons utilized the approach of "The Power of Choice: Helping Youth Make Healthy Eating and Fitness Decisions" [43], and included 'hands-on" learning via preparation of low-cost, culturally appropriate foods, taste testing, and exposure to new foods and ingredients. Lessons were conducted with a minimum of equipment in modest facilities, and aimed to develop knowledge, challenge children to identify healthy options and make healthier food choices within usual settings of fast food outlets and corner stores, set personal goals, and self-assess in order to refine goals. Nutrition topics were sequenced as follows: making low fat choices, increasing fruit and vegetables, replacing sugar and portion size, replacing refined with whole grains, healthy snacks and hunger cues, moderation and a balanced diet.

\section{Self-esteem component}

Core self-esteem lessons were developed based on the widely-used curricula, Body Positive [44], a program designed to promote health at every size, body satisfaction and self-esteem, and Kwanza-based activities designed to promote cultural pride and build community. As needs became evident, health and behavior lessons were adapted from the approach of Kids' Health [45] to address topics such as hygiene, acne, puberty, anger management, bullying, and being teased. Self-esteem topics were sequenced as follows: self awareness \& cultural expression of self, positive interaction, effective communication, Body Positive, 'Health At Every Size' \& respect of self and others, taking charge of your personal hygiene, overcoming challenges (including bullying, teasing and conflict), self-assessment of personal challenges, and positive growth.

\section{Physical activity component}

Activities were designed to consider the body weight and fitness status of children, with gradual and manageable increases in difficulty, duration and frequency. Activities, based on the After-School SPARK [46] physical activity program, were child-centered, encouraged enthusiasm and participation, and aimed to increase enjoyment through games, dance and sports. Physical activity programming was sequenced as follows: flexibility, strength- 
ening, endurance, balance and coordination, speed and agility. Children were encouraged to be active daily even when family members or peers were not, including outside of TAT program time; for this purpose all children received a free YMCA membership, allowing access to the facility. Although we acquired evidence that children used these free memberships to utilize the YMCA facilities, their effectiveness at increasing the overall activity of children outside of program could not be selectively determined within the design of this study.

\section{Parent programming}

Studies of obesity prevention have shown that parental involvement is critical to substantively alter children's dietary intakes and energy expenditures [47]. For adult family members, monthly mailing of health education materials, educational meetings (including advertisements about other free, family-focused healthy lifestyle events available in the community that supported TAT goals), phone calls, and/or in-home visits to target overcoming barriers to adopting healthy behaviors, were scheduled. Also 3 healthy lifestyle events and family celebrations were scheduled for intervention group children and families. At the completion of year-end evaluations and data collection, a celebratory family event honored and acknowledged the gains of the child participants.

Parents/guardians were invited also to nine 1-2 hr sessions each year. The curriculum for adult family members in the intervention group relied on the interactive (discussion, information, and food \& physical activity demonstrations) "Eating Smart. Being Active" adult EFNEP lessons regarding the importance of physical activity; meal planning, food shopping, reading food labels; increasing intakes of vegetables, fruit, whole grains and calcium-rich foods; portion control; and approaches to limiting intakes of fat, sugar and salt http://efnep.ucdavis.edu/AdultCurriculum.html.

\section{Outcome and process evaluation}

Data collection (Table 1) was designed to allow the effects of intervention to be determined on the primary outcome variable (insulin resistance) and on intermediate outcomes (dietary intakes, physical activity). Changes in behaviors (self efficacy, self esteem) expected to precede changes in primary and intermediate outcomes also were assessed. Finally, collection of data for potential modifiers facilitated increased statistical power by their inclusion, if indicated, as covariates. Outcome evaluations were performed at baseline, and after one and two years of intervention. To maximize objectivity, evaluation staff were different from intervention staff. Process evaluation data were collected to assess the quantity and quality of program services delivered, and responses of child partici- pants, adult participants, paid staff and volunteers (Table 7).

\section{Discussion \\ Lessons learned \\ Glucoregulation}

Analyses performed to date show that the intervention program stabilized or improved glucoregulation in children after 1 year, the effect being larger in boys than in girls [48]. Also, a larger percentage of children in the treatment group (vs. control) decreased BMI z-scores after 1 yr.

\section{Additional behavioral components for children}

Before adequate focus could be placed on health topics, we learned that children needed to develop tools to modify their own behavior. As needs became evident, additional curricula components were developed to address these needs. Furthermore, to manage behavior, create a better learning environment, and increase enjoyment, staff was trained to use positive behavioral modification strategies in all program components. To meet these under-anticipated needs, additional staff training was incorporated, and on-going training and staff support was provided by mentoring and weekly discussion. Further, lessons were developed as needed to address community (eg. neighborhood violence), national (eg. Hurricane Katrina) or international (eg. flooding) disasters that affected the participants and their families. We have recently reported that parent-reported post-intervention scores favored the intervention condition for three of the four key psychobehavioral composities that were evaluated cross-sectionally [49].

\section{Additional strategies to engage parents}

Attendance of adult family members at family-focused programming was low due to numerous compelling and competing demands (single parent households, multiple jobs, other children). To address this and facilitate ongoing communication, three alternative forms of engagement were implemented -- telephone calls, home visits, and monthly newsletters. Telephone calls were provided weekly or monthly as needed to help families address barriers to targeted behavioral change and promote family support of child participants. Study staff also provided this support during in-home visits. Families responded very favorably to telephone communication and in-home visits, particularly during times of family struggle, citing the "bridging" effect this created between family and program, an effect that increased program retention. Monthly newsletters were provided which included recipes the children made, monthly programmatic goals, information on free and low-cost health-promoting community activities, and educational materials regarding the importance of healthy food choices and physical activity. 
Table 7: Process Evaluation Data Collection in Taking Action Together

\begin{tabular}{ll}
\hline Variables & Methods and Frequency ${ }^{1}$ \\
\hline Adherence to schedule of lessons & $\begin{array}{l}\text { Observation - monthly for child component; twice per year for adult component } \\
\text { Log - recorded weekly; reviewed monthly } \\
\text { Observation - monthly for child component; twice yearly for adult component } \\
\text { Fidelity of lesson delivery }\end{array}$ \\
$\begin{array}{l}\text { Session evaluation forms - recorded weekly, reviewed monthly } \\
\text { Training, support and monitoring of staff }\end{array}$ & $\begin{array}{l}\text { Observation of attendance and engagement } \\
\text { Observation of lesson delivery - bimonthly (child component), twice per year (adult) }\end{array}$ \\
Response of participants to sessions & $\begin{array}{l}\text { Attendance log - by session; reviewed monthly } \\
\text { Session evaluation form - administered lesson-by-lesson (child component), twice per } \\
\text { year (adult) }\end{array}$ \\
Response of staff and volunteers to sessions & $\begin{array}{l}\text { Session evaluation form - administered lesson-by-lesson for child sessions } \\
\text { Meeting of staff and volunteers - twice per year }\end{array}$ \\
Family response to mailings & Telephone survey - contact intervention families once per year \\
Overall assessment of program & Confidential telephone survey of intervention families - end of year
\end{tabular}

\section{Transportation issues}

Even though children were recruited from neighborhoods near the YMCA sites, we learned early that attendance was improved if rides were provided for afterschool and evening events. Transportation played an important role, as children were not allowed by their families to walk or bicycle to the facilities because of safety concerns. While this was an unforeseen cost (necessitating the hiring of a van and van driver), it improved attendance and reliability of outcome measures for this proofof-concept pilot project. Subsequent implementation efforts should avoid this issue by delivering the program within established after-school settings.

\section{Community bonds}

Participation in this study proved to be an intense and influential experience for all involved. Staff gained new respect for the resourcefulness of children and their families, and were struck by the immense negative effect of neighborhood violence on attitudes, behaviors and activities. Family members, who were initially reserved and distrustful, later expressed gratitude that their children could be truly supported and cared for by persons outside their immediate community. Although we initially focused on the importance of a sound educational strategy, we later placed this third - after providing for the primary needs of participants, and the behavioral skills needed to receive the programming offered to them. Lastly, while we initially provided inexpensive incentives for attendance (e.g., athletic equipment, recipe books), these failed to serve their intended purpose. Instead, the children and families responded most profoundly to involvement at the personal level. Subsequent implementation efforts should seek strong interpersonal skills in staff and volunteers.

\section{Interpretation}

We attempted to incorporate into TAT the lessons learned from previous programs to prevent T2DM in children. Specifically, we included a multi-disciplinary team, attempted to involve parents/guardians, targeted the most promising nutrition and physical activity goals for intervention, emphasized experiential learning, and developed and delivered a program that children enjoyed and wanted to attend.

Although nutrition and physical activity have been the usual targets of T2DM prevention programs, the inclusion of self esteem is unique to TAT. Additionally, TAT included a psycho-behavioral component that was essential to address the unique challenges faced by lowincome, inner-city children. To our knowledge this is one of few studies to evaluate both biological and sociological responses to an intervention in children. Unlike schoolbased programs, this non-school program has the potential to be a sustainable, highly accessible physician-referral program for children identified at high risk of weight gain and associated complications.

Several opportunities were noted for program expansion by inclusion of other ethnic groups, and intensification via daily delivery in after-school venues. The lowincome, inner-city African American population targeted by TAT faces a higher risk of chronic disease compared to other groups, a gap that continues to widen [5], and a disproportionate share of obstacles -- single parenthood, job insecurity, violence, inadequate medical care, discrimination, and suboptimal housing. An intervention that can successfully overcome these barriers may, with comparative ease, be translated to other populations. Demonstrating efficacy in other ethnic groups will suggest generalizability of the intervention for inner-city American youth. 
It is unrealistic to expect healthy behaviors to become ingrained after one or even two years. However, demonstrating significant impact in one year is justification for continuation. Our long-term goal is that TAT, with minimal external support, could be institutionalized and continued long after the research is over, extending reach to many more children and families in other out-of-school settings here and elsewhere.

In conclusion, this protocol evaluates the theory of self efficacy to improve children's dietary intake, physical activity, and self esteem. Improved glucoregulation in children after this intervention [48] suggests that the TAT protocol has a great potential to serve as a guideline protocol for future interventions in children's health related area; and the more favorable psychobehavioral scores for children in the intervention group [49]suggest potential for improvements in characteristics that may broadly influence a child's ability to be successful in school and elsewhere. Assessment of the extent to which the program achieves its aims will depend on approaches, designs and other individual factors related to the area of intervention.

\section{Limitations}

This pre-post non-randomized experimental design did not allow differences due to program site to be evaluated, since the control program was delivered at one site and the treatment program at another. A follow-up site-randomized controlled study would be needed to determine whether similar differences between treatment group status would be observed under this more rigorous design. Results suggest that such a follow-up study is justified. This study also did not evaluate efficacy is children either younger than $9 \mathrm{yr}$ or older than $10 \mathrm{yr}$; it did not evaluate efficacy in children of ethnicities other than AfricanAmerican; and it did not evaluate efficacy in middle-or upper-income populations. Until additional studies are performed, these data cannot be extrapolated to the breadth of children in America or elsewhere.

\section{Competing interests}

The authors declare that they have no competing interests.

\section{Authors' contributions}

LDR was involved in conceptualizing the study, implementation, evaluation and manuscript preparation. SS was involved in manuscript preparation and submission. $\mathbf{J}$ contributed in conceptualizing the study. RAM, AR and BSG were involved in implementation and evaluation. SEF supervised conceptualizing of the study, implementation, evaluation and manuscript preparation and was also the Principle Investigator of the intervention.

\footnotetext{
Acknowledgements

The authors gratefully acknowledge the wonderful collaboration of the YMCA of the East Bay in Oakland, CA. Essential funding for program development was provided by USDA CSREES grants 2004-35214-14254 and 2005-35215-15046, the Agriculture Experiment Station and the YMCA. The authors are indebted to the participating children and their families, the talented staff of Children's Hospital of Oakland, UC Berkeley student assistants, all members of the TAT Advisory Board, and to dedicated staff including Camille Cyrus, Mark Fitch, Molly Fyfe, and Matt Johnson.
}

\section{Author Details}

1Dr Robert C and Veronica Atkins Center for Weight and Health, University of California, Berkeley, CA 94720-3100, USA and 2Department of Nutritional Sciences and Toxicology, University of California, Berkeley, CA 94720-3104, USA

Received: 23 October 2009 Accepted: 21 May 2010

Published: 21 May 2010

\section{References}

1. Dabelea D, Bell RA, D'Agostino RB Jr, Imperatore G, Johansen JM, Linder B, Liu LL, Loots B, Marcovina S, Mayer-Davis EJ: Incidence of diabetes in youth in the United States. JAMA 2007, 297(24):2716-2724.

2. Anonymous: Type 2 diabetes in children and adolescents (Consensus Statement, Am Diabetes Assoc). Diabetes Care 2000, 23:381-389.

3. Goran MI, Bergman RN, Cruz ML, Watanabe R: Insulin resistance and associated compensatory responses in African-American and Hispanic children. Diabetes Care 2002, 25(12):2184-2190.

4. Narayan KM, Boyle JP, Thompson TJ, Sorensen SW, Williamson DF: Lifetime risk for diabetes mellitus in the United States. JAMA 2003, 290(14):1884-1890.

5. Life and Death from Unnatural Causes: Health and Social Inequity in Alameda County. [http://www.acphd.org/AXBYCZ/Admin/ DataReports/00 2008 full report.pdf

6. Nwobu CO, Johnson CC: Targeting obesity to reduce the risk for type 2 diabetes and other co-morbidities in African American youth: a review of the literature and recommendations for prevention. Diab Vasc Dis Res 2007, 4(4):311-319.

7. About the YMCA [http://www.ymca.net]

8. Annesi JJ, Westcott WL, Faigenbaum AD, Unruh JL: Effects of a 12-week physical activity protocol delivered by YMCA after-school counselors (Youth Fit for Life) on fitness and self-efficacy changes in 5-12-year-old boys and girls. Res Q Exerc Sport 2005, 76(4):468-476.

9. Barbeau P, Johnson MH, Howe CA, Allison J, Davis CL, Gutin B, Lemmon CR: Ten months of exercise improves general and visceral adiposity, bone, and fitness in black girls. Obesity (Silver Spring) 2007, 15(8):2077-2085.

10. Robinson TN, Killen JD, Kraemer HC, Wilson DM, Matheson DM, Haskell WL, Pruitt LA, Powell TM, Owens AS, Thompson NS: Dance and reducing television viewing to prevent weight gain in African-American girls: the Stanford GEMS pilot study. Ethn Dis 2003, 13(Suppl 1):S65-77.

11. Story M, Sherwood NE, Himes JH, Davis M, Jacobs DR Jr, Cartwright $Y$, Smyth M, Rochon J: An after-school obesity prevention program for African-American girls: the Minnesota GEMS pilot study. Ethn Dis 2003, 13(Suppl 1):S54-64.

12. Yin Z, Gutin B, Johnson MH, Hanes J Jr, Moore JB, Cavnar M, Thornburg J, Moore D, Barbeau P: An environmental approach to obesity prevention in children: Medical College of Georgia FitKid Project year 1 results. Obes Res 2005, 13(12):2153-2161.

13. 2000 Growth Charts [http://www.cdc.gov/growthcharts]

14. Matsuda M, DeFronzo RA: Insulin sensitivity indices obtained from oral glucose tolerance testing: comparison with the euglycemic insulin clamp. Diabetes Care 1999, 22(9):1462-1470.

15. Gunczler P, Lanes R: Relationship between different fasting-based insulin sensitivity indices in obese children and adolescents. J Pediatr Endocrinol Metab 2006, 19(3):259-265.

16. Uwaifo Gl, Nguyen TT, Keil MF, Russell DL, Nicholson JC, Bonat SH, McDuffie JR, Yanovski JA: Differences in insulin secretion and sensitivity of Caucasian and African American prepubertal children. J Pediatr 2002, 140(6):673-680.

17. Silfen ME, Manibo AM, McMahon DJ, Levine LS, Murphy AR, Oberfield SE: Comparison of simple measures of insulin sensitivity in young girls with premature adrenarche: the fasting glucose to insulin ratio may be a simple and useful measure. J Clin Endocrinol Metab 2001, 86(6):2863-2868.

18. Lee JM, Herman WH, McPheeters ML, Gurney JG: An epidemiologic profile of children with diabetes in the U.S. Diabetes Care 2006, 29(2):420-421.

19. Bry L, Chen PC, Sacks DB: Effects of hemoglobin variants and chemically modified derivatives on assays for glycohemoglobin. Clin Chem 2001, 47(2):153-163.

20. Anonymous: Sickle Cell Trait and Other Hemoglobinopathies and Diabetes. NIH Pub No 09-6287. 2008. 
21. Reinehr T, Kiess W, Andler W: Insulin sensitivity indices of glucose and free fatty acid metabolism in obese children and adolescents in relation to serum lipids. Metabolism 2005, 54(3):397-402.

22. Bandaru A: Social Learning Theory. Englewood Clifs, NJ: Prentice Hall; 1997.

23. Annesi JJ: Relations of physical self-concept and self-efficacy with frequency of voluntary physical activity in preadolescents: implications for after-school care programming. J Psychosom Res 2006, 61(4):515-520.

24. Huang TT, Goran Ml: Prevention of type 2 diabetes in young people: a theoretical perspective. Pediatr Diabetes 2003, 4(1):38-56.

25. Ritchie LD, Ganapathy S, Woodward-Lopez G, Gerstein DE, Fleming SE: Prevention of type 2 diabetes in youth: etiology, promising interventions and recommendations. Pediatr Diabetes 2003 4(4):174-209.

26. Woodward-Lopez G, Ritchie LD, Gerstein DE, Crawford PB: Obesity: Dietary and Developmental Influences. Boca Raton FL: CRC Press Taylor \& Francis Group; 2006.

27. Physical activity guidelines for Americans [http://www.health.gov/ paguidelines]

28. Spear BA, Barlow SE, Ervin C, Ludwig DS, Saelens BE, Schetzina KE, Taveras EM: Recommendations for treatment of child and adolescent overweight and obesity. Pediatrics 2007, 120(Suppl 4):S254-288.

29. Wardle J, Cooke L: The impact of obesity on psychological well-being. Best Pract Res Clin Endocrinol Metab 2005, 19(3):421-440.

30. Lowry KW, Sallinen BJ, Janicke DM: The effects of weight management programs on self-esteem in pediatric overweight populations. J Pediatr Psychol 2007, 32(10):1179-1195.

31. Kratina K: Health at every size. Healthy Weight J 2003, 17:19-23.

32. Reinehr T, de Sousa G, Andler W: Longitudinal analyses among overweight, insulin resistance, and cardiovascular risk factors in children. Obes Res 2005, 13(10):1824-1833.

33. Grufferman S: Complexity and the Hawthorne effect in community trials. Epidemiology 1999, 10(3):209-210.

34. Reynolds C: Behavior Assessment System for Children (BASC-2). 2nd edition. Edited by: Bloomington MN. Pearson Assessments; 2004.

35. United States Department of Agriculture. What's in the Foods You Eat search tool, Version 2.0 [http://www.ars.usda.gov/ba/bhnrc/fsra]

36. Friday JE, Bowman SA: MyPyramid equivalents database for USDA survey food codes, 1994-2003, version 1.0. U.S. Department of Agriculture, Agriculture Research Service; 2006.

37. Rothman KJ: No adjustments are needed for multiple comparisons. Epidemiology 1990, 1(1):43-46.

38. Strauss A, J C: Grounded theory methodology: An overview. In Handbook of Qualitative Research Edited by: Denzen N. Newbury Park: Sage; 1994:273-285

39. Ferguson MA, Gutin B, Le NA, Karp W, Litaker M, Humphries M, Okuyama $T$, Riggs $S$, Owens $S$ : Effects of exercise training and its cessation on components of the insulin resistance syndrome in obese children. Int J Obes Relat Metab Disord 1999, 23(8):889-895.

40. Freemark $M$, Bursey D: The effects of metformin on body mass index and glucose tolerance in obese adolescents with fasting hyperinsulinemia and a family history of type 2 diabetes. Pediatrics 2001, 107(4):E55.

41. Tershakovec AM, Kuppler KM, Zemel BS, Katz L, Weinzimer S, Harty MP Stallings VA: Body composition and metabolic factors in obese children and adolescents. Int J Obes Relat Metab Disord 2003, 27(1):19-24.

42. McMurray RG, Bauman MJ, Harrell JS, Brown S, Bangdiwala SI: Effects of improvement in aerobic power on resting insulin and glucose concentrations in children. Eur J App/ Physiol 2000, 81(1-2):132-139.

43. Anonymous: The Power of Choice: Helping Youth Make Healthy Eating and Fitness Decisions. Team Nutrition: USDA Food and Nutrition Service; 2003

44. The Body Positive [http://www.thebodypositive.org]

45. Kids' Health Ages 6-12 [http://www.cyh.com]

46. Anonymous: SPARK After-School Curriculum. San Diego CA; 2006

47. Ritchie $L$, Hoelscher $M$, Sothern $M$, Crawford P: Position of the American Dietetic Association: Individual-, family-, school-, and communitybased interventions for pediatric overweight. J Am Diet Assoc 2006, 106:925-945.

48. Raman A, Ritchie LD, Lustig RH, Fitch MD, Hudes ML, Fleming SE: Insulin resistance is improved in overweight African American boys but not in girls following a one-year multidisciplinary community intervention program. J Ped Endocrin Met 2010, 23(1-2):109-120
49. Stone S, Raman A, Fleming SE: Behavioral characteristics among obese/ overweight inner-city African American children: A secondary analysis of participants in a community-based Type 2 diabetes risk reduction program. Children Youth Services Rev 2010, 32:833-839.

50. Raman A, Fitch M, Hudes M, Lustig R, Murray C, Ikeda J, Fleming S: Baseline correlates of insulin sensitivity in inner city high BMI African American children. ObesityAdvance online publication, 26 June 2008 (doi:101038/oby2008329) 2008, 16(9):2039-2045

51. Horlick M, Arpadi SM, Bethel J, Wang J, Moye J Jr: Bioelectrical impedance analysis models for prediction of total body water and fat-free mass in healthy and HIV-infected children and adolescents. Am J Clin Nutr 2002, 76(5):991-999.

52. Lewy VD, Danadian K, Arslanian S: Determination of body composition in African-American children: validation of bioelectrical impedence with dual energy X-ray absorptiometry. J Pediatr Endocrinol Metab 1999, 12(3):443-448

53. Burke JP, Hale DE, Hazuda HP, Stern MP: A quantitative scale of acanthosis nigricans. Diabetes Care 1999, 22(10):1655-1659.

54. Crawford PB, Obarzanek E, Morrison J, Sabry Zl: Comparative advantage of 3-day food records over 24-hour recall and 5-day food frequency validated by observation of 9- and 10-year-old girls. J Am Diet Assoc 1994, 94(6):626-630

55. Kimm SY, Glynn NW, Kriska AM, Fitzgerald SL, Aaron DJ, Similo SL, McMahon RP, Barton BA: Longitudinal changes in physical activity in a biracial cohort during adolescence. Med Sci Sports Exerc 2000, 32(8):1445-1454.

56. Kelder S, Hoelscher DM, Barroso CS, Walker JL, Cribb P, Hu S: The CATCH Kids Club: a pilot after-school study for improving elementary students' nutrition and physical activity. Public Health Nutr 2005 8(2):133-140.

57. Hay J: Adequacy and predilection for physical activity in children. Clin J Sport Med 1992, 2:192-201.

58. Ritchie LD, Raman A, S S, Fitch MD, Fleming SE: Dietary intakes of urgan, high BMI, African American children: Family and child dietary attributes predict child intakes. J Nutr Educ Behav 2010 in press.

59. Harter S: Self-perception profile for children. University of Denver; 1985

60. Hay J: Predicting the selection of physical education class in grade ten from self-perceptions reported in grades sever, eight, and nine. Brock Educ 1996, 6:59-69.

61. Pulvers KM, Lee RE, Kaur H, Mayo MS, Fitzgibbon ML, Jeffries SK, Butler J, Hou Q, Ahluwalia JS: Development of a culturally relevant body image instrument among urban African Americans. Obes Res 2004, 12(10):1641-1651

62. Field AE, Franko DL, Striegel-Moore RH, Schreiber GB, Crawford PB, Daniels SR: Race differences in accuracy of self-reported childhood body size among white and black women. Obes Res 2004, 12(7):1136-1144.

63. Shankar S, A K: Influences of fruit and vegetable procurement and consumption among urban African-Amercian public housing residents, and potential stategies for intervention. Family Econ Nutr Rev 2001, 13:34-46.

64. Siero FW, Broer J, Bemelmans WJ, Jong Meyboom-de BM: Impact of group nutrition education and surplus value of Prochaska-based stage-matched information on health-related cognitions and on Mediterranean nutrition behavior. Health Educ Res 2000, 15(5):635-647.

65. Greene GW, Rossi SR: Stages of change for reducing dietary fat intake over 18 months. J Am Diet Assoc 1998, 98(5):529-536.

66. Laforge RG, Rossi JS, Prochaska JO, Velicer WF, Levesque DA, McHorney CA: Stage of regular exercise and health-related quality of life. Prev Med 1999, 28(4):349-360

67. Moos R, Moos B: Family Environment Scale Manual. 2nd edition. Palo Alto, CA: Consulting Psychologists Press; 1986.

68. American Diabetes Association:Risk test [http://www.diabetes.org/risktest/text-version.jsp]

69. Raman A, Lustig RH, Fitch MD, Fleming SE: Accuracy of self-assessed Tanner staging against hormonal assessment of sexual maturation in overweight African-American children. J Ped Endocrin Metab 2009 22:609-622.

doi: $10.1186 / 1745-6215-11-60$

Cite this article as: Ritchie et al., Taking Action Together: A YMCA-based protocol to prevent Type-2 Diabetes in high-BMI inner-city African American children Trials 2010, 11:60 